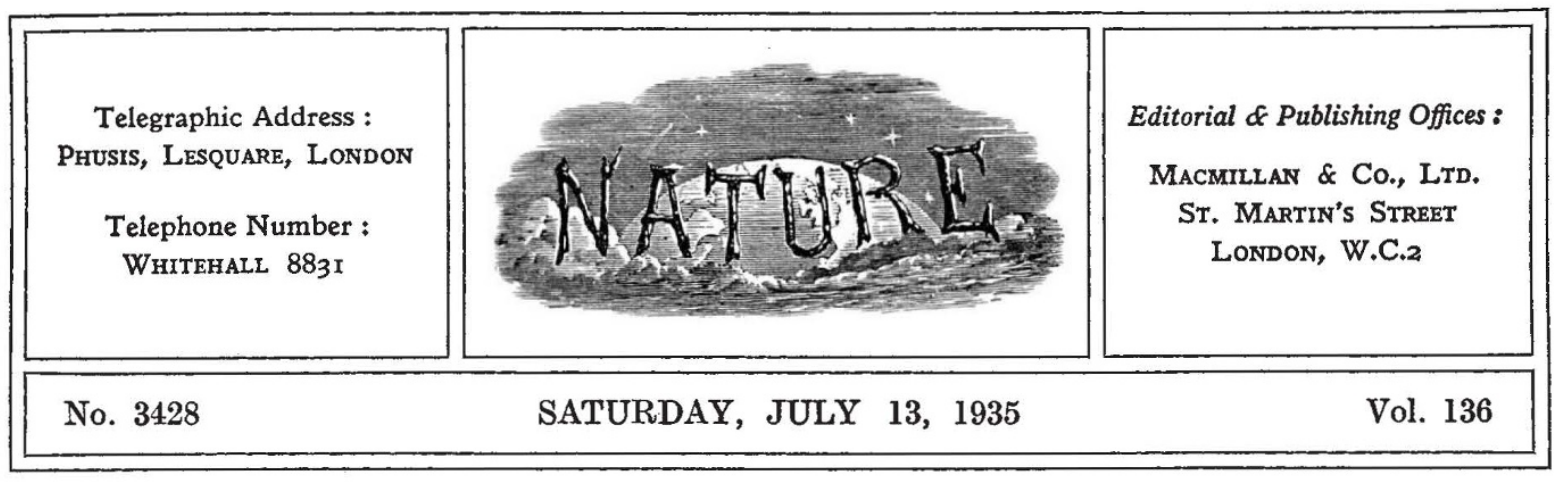

\title{
Scientific Management and Social Problems
}

$\mathrm{T}$ HE sixth International Conference on Scientific Management, which opens on July 15 , comes at a time when the whole contribution of science not merely to industrial efficiency but also to every aspect of national and social welfare is receiving a searching examination. While on one hand there is a growing recognition that readjustments are required in our political and economic policies to enable us to take full human advantage of this age of science, technology and power production, while most people are disposed to regard a shorter working day or a shorter working week as an inevitable consequence of technological advance and as a desirable if not essential means of securing a wider distribution of leisure, there are strong forces setting in exactly the opposite direction.

The recognition that social control has not kept pace with the social change induced by scientifio research and its applications has not always stimulated a resolve to use the full powers of the economy of science, technology and power production which man's genius has created. On the contrary, it has also induced the rise of a defeatism spirit which deliberately renounces many of the advantages with which the application of scientific thought and discovery can endow mankind, and attempts to return to the methods and conditions of the past. There is, in fact, a grave danger of a widespread revolt against science and of a social throttling of research, and the warning of Glenn Frank in "America's Hour of Decision" has a validity far beyond that of the American position of which he was particularly writing.

The obvious futility of attempting to set back the clock of progress should not lead scientific workers into the error of rejecting such warnings superficially. It must be recognised that, in the new civilisation created under the impact of science and technology, social change has so far outstripped institutional change that the survival of our social order has been in serious doubt in more countries than one. Neither a people nor a Government can be hastily condemned if under such conditions it clutches at any method to avert disaster. The task of the scientific worker is thus that of endeavouring to show a more effective alternative. What is required is a concerted effort by scientific workers, in physical and in social science, to plan the prosecution and publication of their research so that the scientific progress of the next twenty-five years shall stabilise and enrich the life of the nation instead of producing further social instability.

The views advanced by Glenn Frank on the situation in the United States deserve the more serious attention because in some countries scientific workers have already lost the freedom which they still enjoy in English speaking countries. Scientific workers must face the fact that the production of new knowledge cannot be regarded as automatically and invariably good. They must also recognise that the responsibility for considering the impact of modern science in modern society is not solely the responsibility of the worker in social science. It is equally the responsibility of the worker in physical science, and careless distinction between social and physical sciences is in fact one of our most serious dangers.

This changed attitude to science is due essentially to factors the influence of which is widespread. A growing dissatisfaction with maladjustments in society, and with the strain on the structure and functions of the political, social and economic 
order due to laissez-faire, is accompanied by a growing disillusionment with research in which the production of new knowledge is unaccompanied by more effective effort to prevent its application causing more troubles than it cures. These factors alone, according to Dr. Frank, have been even more instrumental than financial stringency in determining the curtailment of expenditure on research in the United States of America in the last two or three years.

The third factor in this attitude to science, the determination to secure better planning and control of political, social and economic developments, enforces the necessity for more effective co-operation between scientific workers themselves. Earlier consideration of the political, social and economic effects of discoveries in the physical sciences or in industrial technology can only be secured by such co-operation. If we are to shorten to any adequate extent the dangerous time lag between the swiftly changing processes of industry and our slowly changing policies, we must develop some means of setting social science to work from the beginning, before social and economic havoc has been produced.

This may well prove an ideal which we cannot entirely realise. However, if it were possible to shorten by even a decade the time lag between technological development and developments in social or economic policy, much would have been done to alleviate distress and maladjustment and to mitigate the opposition to the spread of science. An advance of this kind presupposes the extensive application of scientific thought and methods to fields where they have scarcely begun to penetrate. It is, principally, over-specialised education which has left us so ill-fitted for the mastery of the problems of social management confronting us to-day.

The full significance of the International Conference for Scientific Management can only be appreciated against such a background as this, in the light of a well-founded determination for better planning and more effective control over the whole field of industry and politics, even if there is implied some restraint of scientific effort or change in its direction. Moreover, there are two basic questions on which the Conference may be expected to throw authoritative light and with which its programme indicates it will deal in some measure.

The first of these questions is that of the training of administrators and of securing an adequate and continuous supply of administrators of the requisite quality. The practice of scientific management depends primarily upon the capacity of the administrator, and if the general level of administration whether in industry or the State is to be raised, we cannot continue to rely upon those fortuitous methods of filling the higher managerial posts which have hitherto been the vogue in most industrial and commercial organisations in Great Britain. Some definite efforts must be made to secure a reservoir of personnel with sufficient initial training and experience to form the startingpoint for selection for promotion to the higher ranks. This must be supplemented by systematic attempts on scientific lines to select from this reservoir those who give the most promise of qualifying for the higher administrative positions, and to ensure that they receive opportunities for further experience and training where required.

The maintenance of progressive prosperity depends largely on the continuous succession of able administrative leaders. It is also linked with the related problem of the place of the expert in modern government. Here, although in some sections of industry it may be fairly claimed that an adequate solution has been found, in social and political affairs the problem has received nothing like the same attention. All too frequently either the expert is allowed to usurp the place of the administrator and dictate policy to the neglect of other factors and the detriment of management, or, especially where the scientific expert is concerned, the administrator has proved incompetent or indifferent to the scientific factors involved.

It may be taken as axiomatic to-day that statesmanship must rest upon a scientific study of the causes of social problems and a statistical study of the results of social policies. The correlation of expert opinion and knowledge with legislative and executive leadership does not mean that policy should be determined primarily by expert advice. The expert is essentially a specialist in means, not in ends. He indicates the facts upon which a wise decision or policy must be based. As Dr. Glenn Frank points out, "the function of the expert is that of hewer of wood and drawer of water to the statesman". It is the latter whose patience and sense of social needs, values and possibilities, added to a knowledge of the facts, enable him to build up the broad policies required.

The real question at issue is how to provide administrators possessing at once the sense of values and the capacity to assess and interpret the 
increasingly technical factors involved in almost every Government decision. The sessions at the Conference to be devoted to management problems arising from Government intervention can scarcely avoid the consideration of this particular question. A certain degree of scientific objectivity at any rate must be secured in public policy, and whether a new orientation of the methods of government as suggested by General Smuts is required, or whether the question is rather one of redressing the educational situation so as to ensure an adequate reservoir of administrators competent to assess scientific and technical factors in government, the matter is one urgently demanding serious study. Only in this way can we attain either the power or the vision to control the forces now at our disposal so as to ensure the maximum advantage to mankind. No less here than in other branches of human endeavour, the fullest freedom to creative thought and effort is an essential element in success, and indeed the only alternative to the renunciation and defeatism already characterising certain nations in this struggle to-day.

\section{Notable Epidemics and their Causes}

\section{Some Notable Epidemics}

By Dr. H. Harold Scott. Pp. xix +272 . (London : Edward Arnold and Co., 1934.) 12s. 6d.net.

FPIDEMIOLOGY, after making slow but steady progress for a century or more in Great Britain, as the outcome of the work of the disciples of Sydenham-the so-called 'Annalists'sustained a severe setback when the Industrial Revolution, with its crowding and neglect of sanitation, facilitated the spread of disease. Dr. John Snow's investigations into the cholera of 1848-49 may thus be said to have inaugurated a new era, making water-borne infection an established reality, and this stimulus, following upon the work of Mead, Pringle, Lind, Baker, Blane, Jenner, Thackrah and the three reports of the Poor Law Commissioners of 1838-39, greatly strengthened the hands of Chadwick and Simon in producing the health crusade of the latter half of the nineteenth century. Almost inevitably, therefore, Dr. Scott's Chapter i commences with an account of the "Broad St. Pump Outbreak" (1854).

It is, perchance, the 'irony of fate' which has determined that Snow's spade-work on this Westminster prevalence, followed as it was by Snow's and Simon's reports on the "Southwark and Vauxhall Water Outbreak" of 1854 and by Netten Radcliffe's report on the "East London Cholera Outbreak" of 1866, firmly established the belief in water-borne disease. There can be no surprise, however, at Sir John Simon's difficulty in accepting "Snow's peculiar doctrine", or his reserve regarding deductions drawn from reports on the cholera prevalences of 1854 and 1866 .

A probable explanation of the difficulties in question, as resulting from failure to recognise the possibility of contemporaneous spread by shellfish, appeared in Public Health (Jan. 1923, pp. 98-106) ; moreover, as regards "The Pump", the official inquiry made at the bidding of a Committee for Scientific Enquiries, in 1855, clearly showed that "many cases in the infected districts occurred of persons who were not in the habit of using the pump water". This Chapter i and Chapters ii-vi, in which Dr. Scott deals with water-borne outbreaks of typhoid fever, at Blackburn (1881), Worthing (1893), Maidstone (1897), Lincoln (1904 5) and Bolton upon Dearne (1921) make exceed. ingly interesting reading; though here, again, there is something to be said (see Public Health, Dec. 1921, pp. 57-59) for the view that other influences than the water supplies were also at fault. It must be remembered that some sixty or more years ago, a president of the Society of Engineers was able to trace all cases of typhoid fever coming under his notice, in London, to faulty drains ; and that in similar fashion water supplies enjoyed an almost complete monopoly of discredit as regards cholera and typhoid fever for several decades.

Chapters vii- $\mathbf{x v}$ present intriguing problems of a like character with reference to milk outbreaks of typhoid fever, diphtheria and scarlet fever; though here the claim to a monopoly for the suspected milk is stronger as a rule than was the case in the water outbreaks-in the case of the "milkborne enteric fever outbreak" in St. Marylebone (1873), at any rate, the anomalies are, indeed, very disturbing; scepticism was voiced, at the time of the prevalence, and the difficulties, regarding "nursery milk" and "extent of involvement of domestic servants", are instanced on p. 61 of the paper in Public Health, Dec. 1921, referred to above. 